\title{
RANCANG BANGUN PROGRAM APLIKASI PEMBELAJARAN AKSARA SUNDA BERBASIS ANDROID
}

\author{
${ }^{1}$ Haerul Fatah, ${ }^{2}$ Nurul Ichsan, ${ }^{3}$ Tri Wahyuni, ${ }^{4}$ Erni Ernawati, ${ }^{5}$ Indriyanti \\ Sistem Informasi, Teknologi Informasi, Universitas Bina Sarana Informatika \\ Jl.Kramat Raya No.98, Senen, Jakarta Pusat \\ Email: haerul.hef@bsi.ac.id, nurul.nrc@bsi.ac.id, tri.twy@bsi.ac.id, erni.ert@bsi.ac.id, \\ indriyanti.iyt@bsi.ac.id
}

(Diterima: 26 Februari 2020, direvisi: 22 April 2020, disetujui: 5 Mei 2020 )

\begin{abstract}
Western culture and technological development gradually began to shift the traditional culture in a country. Traditional culture is a characteristic and asset of an area that should be preserved and remain preserved. One of them is the Sundanese script culture in Indonesia, especially in West Java. Like it or not, we have to keep up with the times and make adjustments to current conditions so that traditional culture can be preserved in this modern era. This research aims to produce applications that can be interesting and not boring Sundanese script learning media so that people are interested in learning Sundanese characters easily and fun. It is hoped that this application can be useful as a medium for preserving and preserving the traditional culture of a Sundanese script by utilizing technological sophistication and following modern culture.
\end{abstract}

Keywords: Modern Age, Traditional Culture, Sundanese Script

\begin{abstract}
ABSTRAK
Budaya barat dan perkembangan teknologi sedikit demi sedikit mulai menggeser budaya tradisional yang ada di suatu Negara. Budaya tradisional merupakan ciri dan asset dari suatu wilayah yang seharusnya dijaga dan tetap dilestarikan. Salah satunya budaya aksara sunda yang ada di Indonesia khususnya daerah jawa barat. Mau tidak mau kita harus mengikuti perkembangan zaman dan melakukan penyesuaian dengan kondisi saat ini agar budaya tradisional bisa tetap dilestarikan di zaman modern ini. Penelitian ini bertujuan untuk menghasilkan aplikasi yang dapat menjadi media pembelajaran aksara Sunda yang menarik dan tidak membosankan, sehingga masyarakat tertarik untuk mempelajari aksara Sunda dengan mudah dan menyenangkan. Diharapkan aplikasi ini bisa bermanfaat sebagai media untuk menjaga dan melestarikan budaya tradisional aksara Sunda dengan memanfaatkan kecanggihan teknologi serta mengikuti budaya modern.
\end{abstract}

Kata Kunci : Zaman Modern, Budaya tradisional, Aksara Sunda

\section{PENDAHULUAN}

Aksara Sunda merupakan hasil karya ortografi masyarakat Sunda yang harus dipelihara dan dilestarikan, karena aksara Sunda adalah warisan budaya yang tidak ternilai harganya. Sosialisasi aksara Sunda masih sangat minim dilakukan, meskipun pemerintah Jawa barat sudah melakukan upaya hokum dalam bentuk Peraturan daerah (Perda) no.5 tahun 2003 dan Surat Keputusan Gubernur no. 434/SK.614/dis-pk/1999 [1].

Kehadiran globalisasi tentunya membawa pengaruh bagi kehidupan suatu negara termasuk Indonesia. Pengaruh tersebut meliputi dua sisi yaitu pengaruh positif dan pengaruh negatif. Pengaruh globalisasi di berbagai bidang kehidupan seperti kehidupan politik, ekonomi, ideologi, sosial budaya dan lain-lain. Tanpa disadari, globalisasi dapat menggeser nilai-nilai budaya yang ada di Indonesia dan mengganti dengan budaya barat. Khususnya dikalangan anak muda yang cenderung lebih tertarik dengan budaya barat dibandingkan dengan budaya kita sendiri. Jika terus dibiarkan bukan tidak mungkin budaya asli kita akan musnah karena anak muda selaku generasi bangsa tidak mengenal dan 
bahkan mulai melupakan budaya asli mereka. Contohnya aksara Sunda, banyak anak muda khusunya para pemuda asli jawa barat yang tidak tahu bahkan tidak mengenal aksara Sunda.

Untuk meningkatkan usaha pemeliharaan dan pemberdayaan aksara Sunda, maka tepat kiranya jika menggunakan program aplikasi pembelajaran aksara Sunda berupa animasi interaktif dan game yang tentu akan sangat berperan penting untuk mensosialisasikan aksara Sunda, karena dengan animasi interaktif, masyarakat akan lebih tertarik dan lebih mudah memahami dalam penulisan aksara Sunda.

Pembelajaran dengan menggunakan m-learning dapat digunakan di masa yang akan datang, dengan tanggapan para pendidik dan siswa berharap dapat menggunakan m-learning dalam pembelajaran. Hal ini dikarenakan m-learning memiliki dampak yang positif bagi para siswa, yaitu dapat memotivasi siswa dan meningkatkan antusias siswa dalam belajar serta menarik siswa dalam memahami materi [2].

Penggunaan mobile learning (M-learning) merupakan pembelajaran yang unik karena siswa dapat mengakses materi pembelajaran setiap waktu sehingga hal ini dapat meningkatkan perhatian siswa dalam memahami materi pelajaran, membuat pembelajaran menjadi pervasif, dan dapat memotivasi siswa [3].

Pengumpulan data dalam penelitian ini dilakukan dengan metode observasi dan studi pustaka. Kegiatan observasi yang dilakukan meliputi pengamatan terhadap game atau animasi interaktif lain yang serupa dengan animasi interaktif yang akan dibuat, sedangkan studi pustaka dengan melakukan peninjauan terhadap beberapa penelitian terkait yang membahas mengenai animasi interaktif ataupun halhal yang berkaitan dengan penelitian yang dilakukan.

Tujuan dari penelitian yang dilakukan adalah membangun sebuah aplikasi aksara Sunda yang menarik dan tidak membosankan, sehingga masyarakat tertarik untuk mempelajari aksara Sunda dengan mudah dan menyenangkan. Manfaat dari aplikasi ini untuk membantu proses belajar mengenai aksara Sunda.

\section{TINJAUAN PUSTAKA}

Miftah Farid Adiwisastra dalam penelitiannya merancang sebuah game kuis interaktif sebagai multimedia pembelajaran drill and practice untuk meningkatkan hasil belajar siswa. Metode yang digunakan dalam penelitian ini adalah metode penelitian dan pengembangan atau Research and Development $(R \& D)$. Menguji kinerja media serta mengetahui tingkat kelayakan game ini diujikan ke lapangan. Diharapkan game ini mampu membantu meningkatkan hasil belajar siswa. Penelitian ini juga bertujuan untuk mengetahui pandangan dan ketertarikan siswa terhadap pembelajaran yang menggunakan multimedia pembelajaran model drill and practice dan untuk melihat validitas atau kelayakan game kuis interaktif yang telah dibangun serta untuk melihat penilaian siswa terhadap multimedia yang telah dikembangkan. Dari penelitian ini didapatkan hasil yaitu hampir seluruh siswa memberikan respon positif mengenai pembelajaran yang menggunakan multimedia pembelajaran model drill and practice dengan game kuis interaktif, siswa memberikan penilaian sangat baik terhadap multimedia pembelajaran game kuis interaktif dengan persentase penilaian sebesar $91.979 \%$, dan mengalami peningkatan hasil belajar [4].

Penelitian yang dilakukan oleh Asti Herliana dan Freddy Agus Renaldi dengan judul "Animasi Interaktif Pembelajaran tari Merak", membuat media animasi interaktif yang berisi tutorial tari burung merak yang dimaksudkan untuk siswa sekolah dasar. Dengan animasi ini setidaknya diharapkan memberikan informasi tentang merak guru tari dari segi visualisasi animasi untuk siswa lebih mudah [5].

Dalam penelitiannya, Mayya Nurbayanti dkk membuat sebuah penelitian yang berjudul "Aplikasi Animasi Interaktif Pencampuran Tiga warna Primer Dan Pengenalan Bentuk Geometri Pada Paud AlMuslimun". Pembangunan aplikasi animasi interaktif pencampuran tiga warna primer dan pengenalan bentuk geometri untuk anak usia dini bertujuan untuk menambah sarana pembelajaran untuk orang tua dan guru dalam menarik perhatian anak untuk belajar mengenal warna dan bentuk dengan menggunakan aplikasi animasi interaktif Di dalam aplikasi ini terdapat proses-proses pembelajaran mengenal pencampuran tiga warna primer dan bentuk geometri dengan dukungan tombol interaktif, gambargambar yang menarik serta audio yang untuk meningkatkan daya serap anak usia dini terhadap isi materi yang ingin disampaikan, serta dilengkapi dengan permainan untuk mengukur keterampilan dan sejauh mana anak mengenal warna dan bentuk. Penggunaan sarana pembelajaran dengan menggunakan teknologi animasi interaktif ini ditinjau dari aspek isi materi, pembelajaran dan tampilan dinilai dapat menarik perhatian anak usia dini serta membantu peran orang tua atau guru dalam mendidik anak lebih kreatif lagi [3]. 
Penelitian Nurcahyo mengutarakan Semakin luasnya kemajuan di bidang teknologi maka pendidik dituntut untuk mengembangkan berbagai macam media pembelajaran. Salah satunya adalah perkembangan teknologi komputer dan handphone. Perkembangan teknologi komputer dapat digunakan untuk membantu dalam pembuatan media pembelajaran, handphone dapat digunakan untuk membantu dalam penerapan dari media pembelajaran tersebut. Sehubungan dengan hal tersebut, guna memanfaatkan kemajuan teknologi yang ada serta hampir setiap siswa memiliki handphone terutama smartphone berbasis android perlu diterapkan media pembelajaran berupa aplikasi android untuk menunjang proses pembelajaran di kelas [6].

Fatimah dalam penelitiannya menyatakan bahwa membuat pembelajaran lebih menarik, siswa dapat mempelajari materi tanpa terbatas waktu, artinya siswa dapat belajar di luar jam pembelajaran, sehingga akan memberikan dampak positif bagi siswa dalam penggunaan smartphone sebagai sarana belajar [7].

Penelitian yang dilakukan Rahmelina mengungkapkan bahwa media pembelajaran dapat mempertinggi proses belajar siswa dalam pembelajaran dan diharapkan dapat menaikkan hasil belajar yang dicapai. Media pembelajaran yang digunakan yaitu perangkat mobile berupa handphone, personal computer, laptop, dan tablet pc. Handphone yang dulunya hanya sebagai alat komunikasi, saat ini sudah dapat merangkum fungsi dan fitur yang lainnya. Aplikasi berbasis Android merupakan inovasi media pembelajaran yang dirasa pas untuk memenuhi kemajuan teknologi informasi dan komunikasi serta memenuhi kebiasaan siswa agar dapat disesuaikan dengan gaya hidup mereka saat ini [8].

Berdasarkan beberapa penelitian diatas, dapat disimpulkan bahwa metode pembelajaran di zaman sekarang harus menyesuaikan dengan perkembangan zaman. Media pembelajaran tidak hanya terpatok pada buku cetak atau penjelasan guru di papan tulis, tapi harus mulai mengembangkan media pembelajaran melalui gadget atau handphone, karena pembelajaran menggunakan aplikasi interaktif yang penuh dengan animasi dan musik akan lebih menarik minat siswa untuk belajar, dan lebih mudah dimengerti jika dibandingkan hanya dengan teori tekstual saja.

\section{METODE PENELITIAN}

Penelitian yang dilakukan merupakan pengembangan sistem. Tahapan yang dilakukan terdiri dari tahap analisis, tahap perancangan, tahap implementasi dan tahap pengujian.

3.1. Analisis

Tahap analisis dilakukan untuk menganalisa kebutuhan dari user, menu/konten apa saja yang dinginkan, sebagai dasar dalam perancangan aplikasi yang akan dibuat. Dilakukan juga studi pustaka dari penelitian-penelitian terdahulu.

\subsection{Perancangan}

Tahap perancangan terdiri atas perancangan alur program, perancangan tampilan, perancangan kuis/game dan perancangan database. Langkah pertama yang dilakukan adalah merancang alur dari program, menentukan menu/konten apa saja yang akan ditampilkan dalam aplikasi, menentukan alur dan penempatan setiap menu dengan baik agar mudah digunakan (user friendly). Tool yang digunakan dalam perancangan alur program menggunakan Microsoft visio. Setelah alur program terbentuk, maka dilakukan pembuatan tampilan dari setiap menu/konten dari aplikasi. Tampilan dibuat semenarik mungkin, dengan menggunakan perpaduan warna dan gambar-gambar yang dapat menambah daya tarik user untuk menggunakan aplikasi. Tool yang digunakan dalam perancangan tampilan menggunakan Adobe Photoshop. Dalam aplikasi yang dirancang dilengkapi juga dengan menu kuis yang berbentuk game, sebagai sarana latihan untuk menguji kemampuan tentang aksara sunda yang telah dipelajari sebelumya. Selanjutnya dibuat sebuah database untuk menyimpan data + nilai hasil dari user yang mengikuti kuis.

3.3. Bangun/Implementasi

Tahap bangun/implementasi terdiri atas implementasi setiap rancangan tampilan dalam aplikasi, implementasi kuis dalam aplikasi dan implementasi database sinkronisasi dengan aplikasi. Tampilan yang telah didesain sebelumnya kemudian diimplementasikan kedalam software. Aplikasi dibuat audio visual, sehingga tidak hanya tampilan visual saja tetapi juga dilengkapi dengan audio musik kecapi suling yang identik dengan khas sunda. Kuis yang telah dirancang kemudian diimplementasikan kedalam software. Untuk menambah minat user dalam mengerjakan kuis, dibuat rangking atau pengurutan 10 besar dari user yang memiliki nilai paling besar. Database yang 
digunakan dalam penelitian ini adalah menggunakan aplikasi SQL Lite yang bisa terkoneksi pada android.

3.4. Pengujian

Tahap pengujian terdiri atas pengujian white box dan black box. Pengujian dilakukan untuk mengetahui apakah aplikasi yang dibuat sudah berjalan sesuai dengan yang diharapkan atau tidak.

\section{HASIL DAN PEMBAHASAN}

Setelah melalui beberapa tahap penelitian, berikut hasil dan pembahasan dari penelitian yang dilakukan:

\subsection{Analisis}

Pada tahap atau fase ini dilakukan untuk mengetahui apa saja yang dibutuhkan oleh pengguna (user), hal ini penting dilakukan agar aplikasi yang akan dibangun sesuai dengan kebutuhan pengguna. Adapun rincian dari analisa kebutuhan yaitu: mengenalkan aksara Sunda, mengenalkan rarangkén pada aksara Sunda, contoh kata menggunakan aksara sunda, lengkap dengan penjelasan dan cara penulisan, kuis berupa pertanyaan-pertanyaan tentang aksara Sunda sebagai sarana latihan dan uji kemampuan.

\subsection{Rancang/Desain}

1. Scene Menu Utama/Home

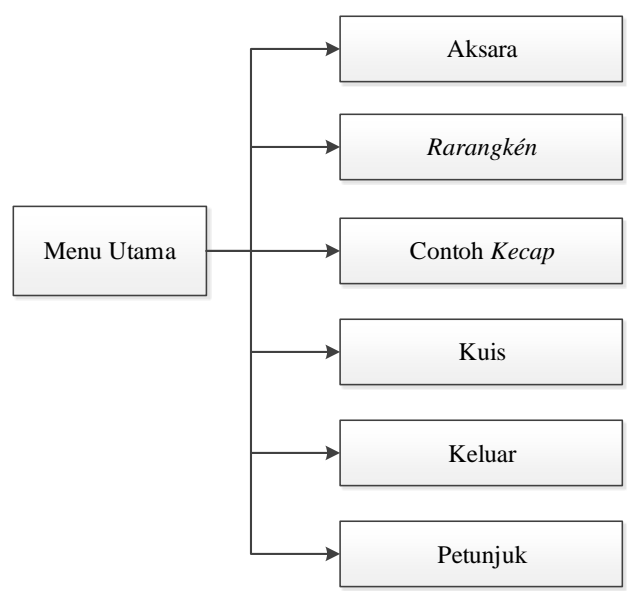

Gambar 1 State transition diagram menu utama

Pada Gambar 1 menunjukan scene menu utama, tampilan awal aplikasi dimana pertama kali user berada di menu utama yang terdapat tombol Aksara, Rarangkén, Contoh Kecap, Kuis, Kaluar dan petunjuk.

2. Scene Menu Petunjuk

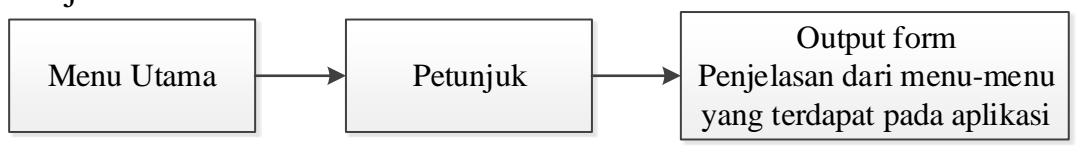

Gambar 2 State transition diagram menu petunjuk

Pada Gambar 2 menunjukan scene menu petunjuk, penjelasan dari menu-menu yang terdapat pada aplikasi, sebagai panduan untuk user agar mudah dalam menggunakannya.

3. Scene Menu Aksara

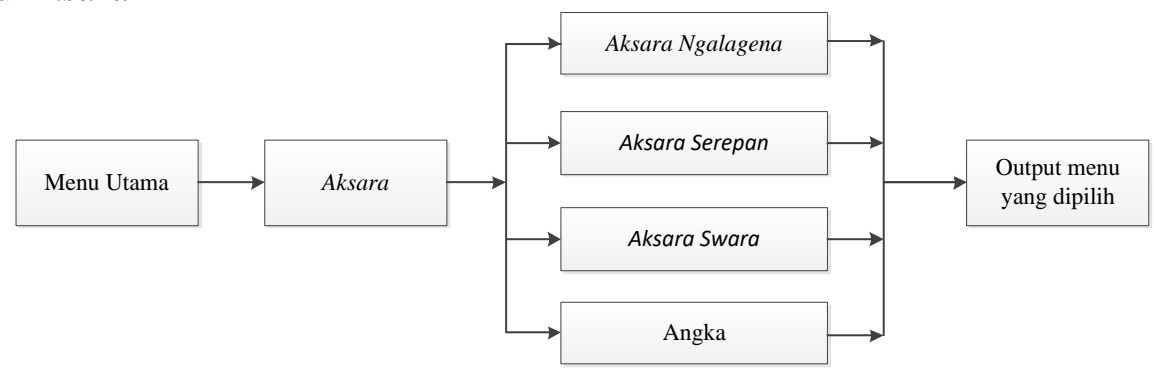

Gambar 3. State transition diagram menu aksara 
Pada Gambar 3 menunjukan scene menu aksara. Agar user mengetahui macam-macam aksara Sunda, maka user harus memilih tombol-tombol yang ada, adapun tombol yang menjadi pilihan tombol aksara ngalagena, aksara serepan, aksara swara, dan angka.

4. Scene Menu Rarangkén

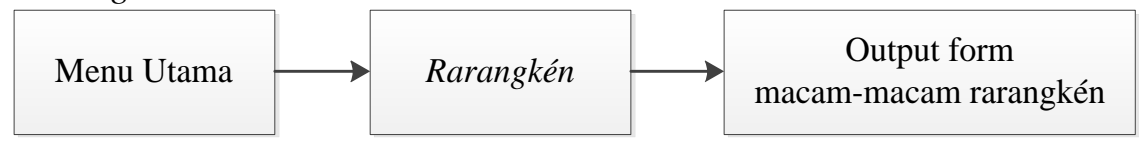

\section{Gambar 4 State transition diagram menu rarangkén}

Pada Gambar 4 menunjukan scene macam-macam rarangkén.

5. Scene Menu Contoh Kecap

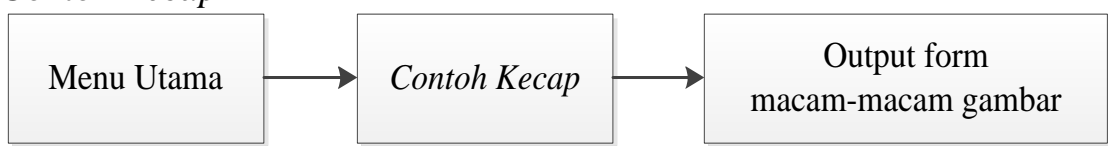

Gambar 5 State transition diagram menu contoh kecap

Pada Gambar 5 menunjukan scene macam-macam gambar.

6. Scene Menu Kuis

Menu Utama

\begin{tabular}{|c|c|c|}
\hline Kuis & $\begin{array}{l}\text { Output form } \\
\text { Biodata }\end{array}$ & $\begin{array}{l}\text { Output form } \\
\text { Kuis }\end{array}$ \\
\hline
\end{tabular}

Gambar 6 State transition diagram menu kuis

Pada Gambar 6 menunjukan scene menu kuis tentang aksara sunda, tersedia 10 pertanyaan dengan tingkat kesulitan yang berbeda-beda.

7. Scene Aksara Ngalagena

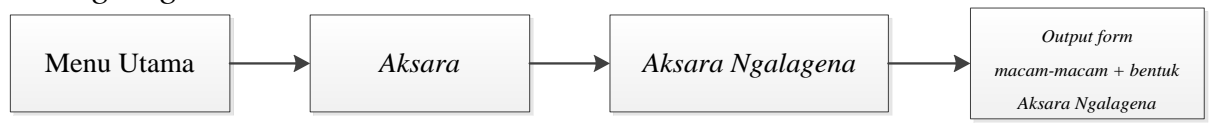

Gambar 7 State transition diagram aksara ngalagena

Pada Gambar 7 menunjukan scene macam-macam aksara ngalagena beserta bentuknya.

8. Scene Aksara Serepan

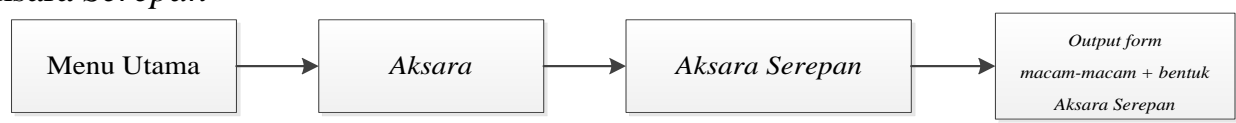

Gambar 8 State transition diagram aksara serepan

Pada Gambar 8 menunjukan scene macam-macam aksara serepan beserta bentuknya.

9. Scene Aksara Swara

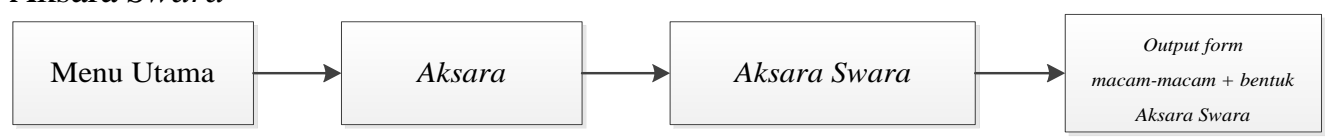

Gambar 9 State transition diagram aksara swara

Pada Gambar 9 menunjukan scene macam-macam aksara swara beserta bentuknya.

10. Scene Angka

Fatah, Rancang Bangung Aplikasi Pembelajaran Aksara Sunda Berbasis Android 


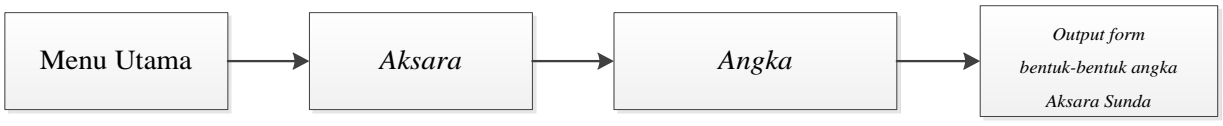

Gambar 10 State transition diagram angka

Pada Gambar 10 menunjukan scene bentuk-bentuk angka aksara Sunda.

11. Scene Penjelasan Rarangkén

\begin{tabular}{|c|c|c|c|}
\hline Menu Utama & Rarangkén & $\begin{array}{l}\text { Output form } \\
\text { macam-macam rarangkén }\end{array}$ & $\begin{array}{c}\text { Output form } \\
\text { penjelasan dari rarangkén } \\
\text { yang dipilih }\end{array}$ \\
\hline
\end{tabular}

Gambar 11 State transition diagram penjelasan rarangkén

Pada Gambar 11 menunjukan scene penjelasan dari rarangkén yang dipilih, lengkap dengan contohnya.

12. Scene Contoh Kecap

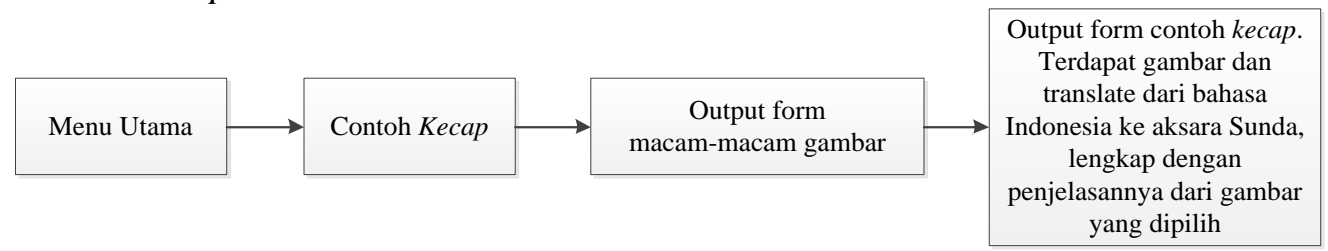

Gambar 12 State transition diagram penjelasan contoh kecap

Pada Gambar 12 menunjukan scene contoh gambar dan translate dari bahasa indonesia ke aksara Sunda lengkap dengan penjelasannya dari gambar yang dipilih.

13. Scene Biodata

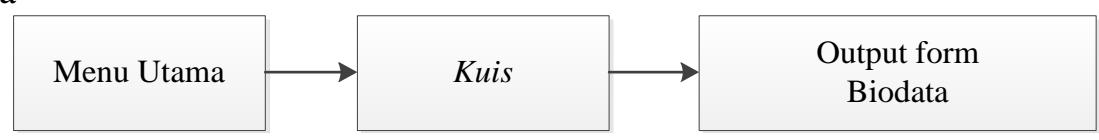

Gambar 13 State transition diagram biodata

Pada Gambar 13 menunjukan scene biodata pemain, berupa text box yang harus diisi oleh pemain untuk disimpan kedalam database.

14. Scene Skor

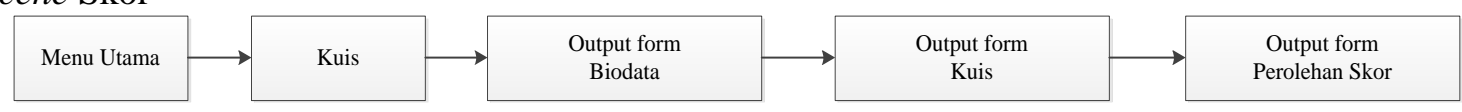

Gambar 14 State transition diagram skor

Pada Gambar 14 menunjukan scene jumlah skor yang diperoleh dan list perolehan skor,terurut dari skor paling tinggi ke skor paling rendah.

15. Scene Database

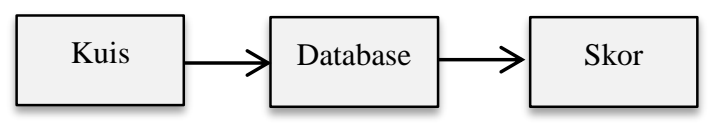

Gambar 15 Scene database

Pada Gambar 15 menunjukan scene rancangan database dari aplikasi yang dibuat. 
16. Bagan alir Aplikasi pembelajaran Aksara Sunda

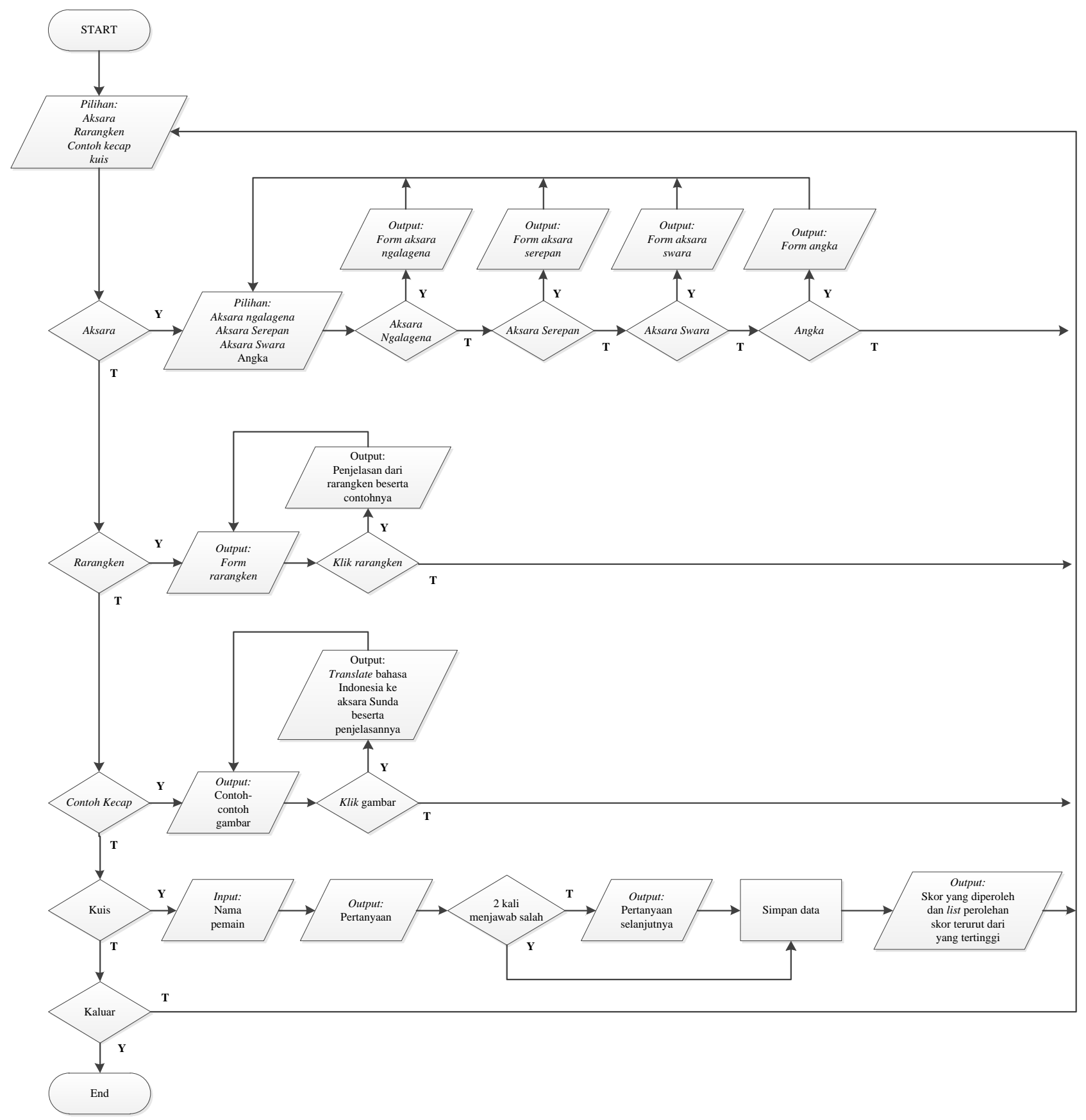

Gambar 16 Bagan alir aplikasi pembelajaran aksara sunda

Pada Gambar 16 menunjukan bagan alir yang menggambarkan alur program aplikasi dari semua menu yang tersedia,

\subsection{Bangun/Implementasi}

Setelah dibuat desain/alur program dari masing-masing scene, selanjutnya implementasi desain pada aplikasi/pembuatan form aplikasi dengan menggunakan pengkodean untuk memproses setiap alur demi alur. Aplikasi yang digunakan pada penelitian ini adalah B4A (Basic For Android).

\subsubsection{Menu Utama/Home}

Berisi 6 tombol. Tombol Aksara untuk masuk ke Menu aksara, tombol Rarangkén untuk melihat macam-macam rarangkén, tombol Contoh Kecap untuk melihat contoh-contoh kata menggunakan aksara Sunda lengkap dengan penjelasannya, tombol Kuis untuk masuk ke menu game berupa pertanyaan- 
pertanyaan tentang aksara Sunda, tombol Keluar untuk keluar dari aplikasi dan tombol Petunjuk untuk melihat penjelasan dari menu-menu yang terdapat pada aplikasi. Tampilan menu utama/home dapat dilihat pada gambar 17.

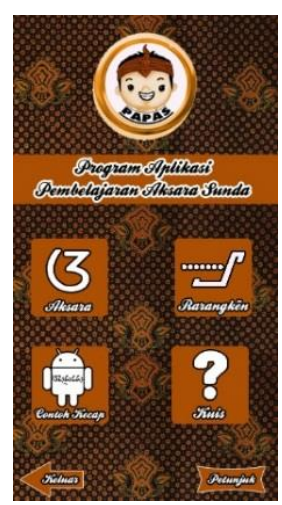

\section{Gambar 17 Tampilan menu utama/home}

\subsubsection{Menu Petunjuk}

Berisi penjelasan dari menu-menu yang terdapat pada aplikasi, sebagai panduan bagi user untuk mempermudah dalam penggunaan. Tampilan menu petunjuk dapat dilihat pada gambar 18 .

\subsubsection{Menu Aksara}

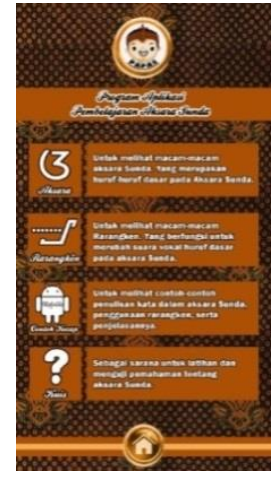

\section{Gambar 18 Tampilan menu petunjuk}

Berisi 5 tombol. Tombol Aksara Ngalagena untuk melihat aksara-aksara ngalagena, Tombol Serepan untuk melihat aksara-aksara serepan, Tombol Aksara Swara untuk melihat aksara-aksara swara, Tombol Angka untuk melihat angka-angka dalam aksara Sunda, dan tombol icon home untuk kembali ke menu utama/home. Tampilan menu aksara dapat dilihat pada gambar 19.

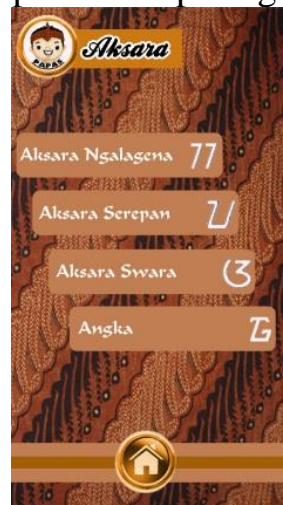

\subsubsection{Menu Rarangkén}

\section{Gambar 19 Tampilan menu aksara}

Berisi macam-macam rarangkén dan tombol icon home untuk kembali ke menu utama/home. 
Tampilan menu Menu rarangkén dapat dilihat pada gambar 20.

\subsubsection{Menu Contoh Kecap}

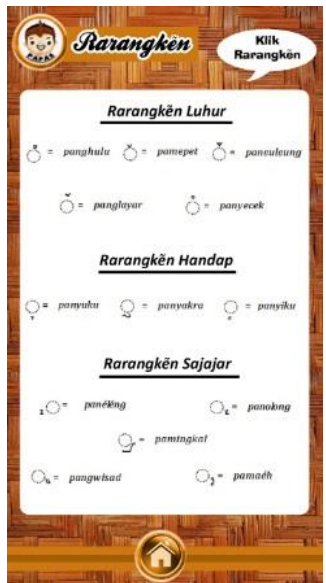

\section{Gambar 20 Tampilan menu rarangkén}

Berisi macam-macam gambar dan tombol icon home untuk kembali ke menu utama/home. Tampilan menu contoh kecap dapat dilihat pada gambar 21.

\subsubsection{Menu Kuis}

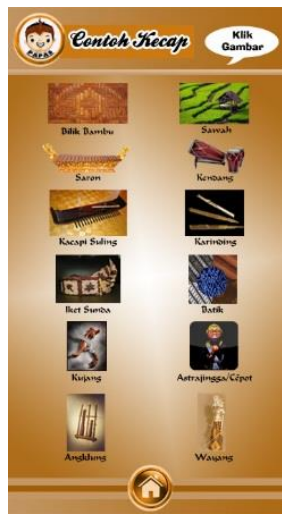

\section{Gambar 21 Tampilan menu contoh kecap}

Berisi pertanyaan tentang aksara sunda, 4 tombol pilihan jawaban/1 text box sebagai tempat untuk menjawab pertanyaan, dan Tombol Jawab untuk mnyimpan jawaban sekaligus pindah ke pertanyaan berikutnya. Tampilan menu kuis dapat dilihat pada gambar 22 dan gambar 23. Gambar 22 merupakan tampilan kuis bentuk pilihan ganda, dan gambar 23 merupakan kuis bentuk essay.

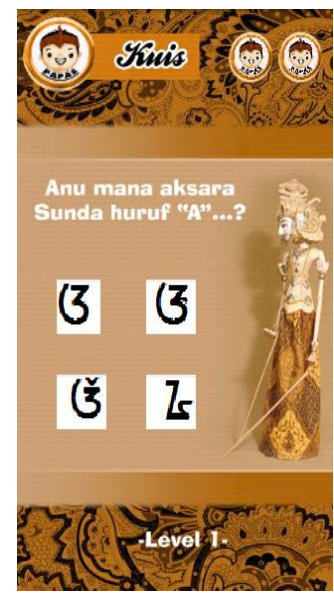

Gambar 22 Tampilan menu kuis a

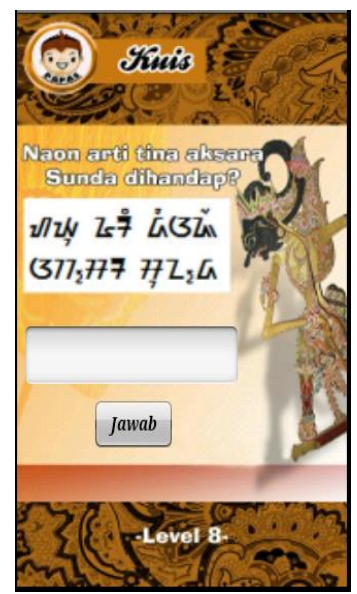

Gambar 23 Tampilan menu kuis b 


\subsubsection{Aksara Ngalagena}

Berisi macam-macam aksara ngalagena beserta bentuknya, Tombol panah untuk kembali ke menu aksara, dan Tombol icon home untuk kembali ke menu utama/home. Tampilan aksara ngalagena dapat dilihat pada gambar 24 .

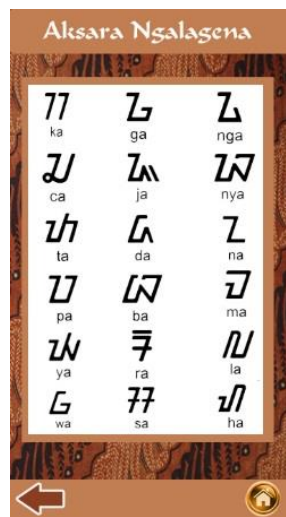

\subsubsection{Aksara Serepan}

\section{Gambar 24 Tampilan aksara ngalagena}

Berisi macam-macam aksara serepan beserta bentuknya, Tombol panah untuk kembali ke menu aksara, dan Tombol icon home untuk kembali ke menu utama/home. Tampilan aksara serepan dapat dilihat pada gambar 25 .

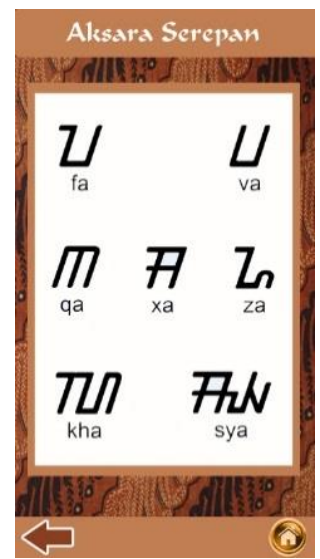

Gambar 25 Tampilan aksara serepan

\subsubsection{Aksara Swara}

Berisi macam-macam aksara swara beserta bentuknya, Tombol panah untuk kembali ke menu aksara, dan Tombol icon home untuk kembali ke menu utama/home. Tampilan aksara swara dapat dilihat pada gambar 26. 


\subsubsection{Angka}

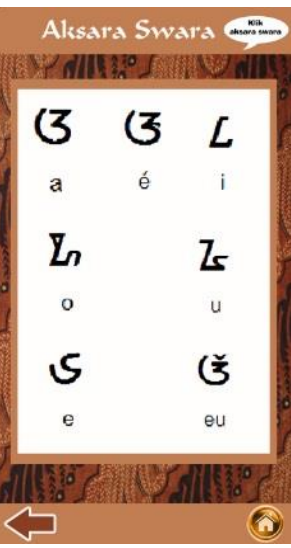

\section{Gambar 26 Tampilan aksara swara}

Berisi macam-macam bentuk angka dalam aksara sunda, Tombol panah untuk kembali ke menu aksara, dan Tombol icon home untuk kembali ke menu utama/home. Tampilan angka dapat dilihat pada gambar 27.

\subsubsection{Contoh Kecap}

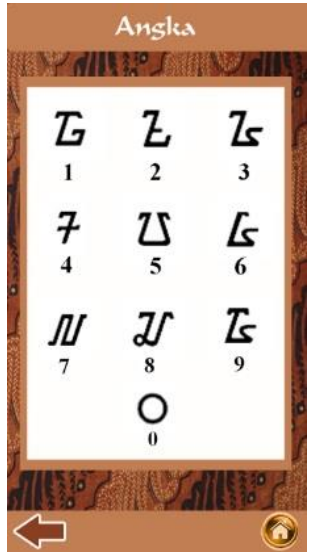

\section{Gambar 27 Tampilan angka}

Berisi contoh gambar, translate dari bahasa indonesia ke aksara Sunda beserta penjelasannya, Tombol panah untuk kembali ke menu aksara, dan Tombol icon home untuk kembali ke menu utama/home. Tampilan contoh kecap dapat dilihat pada gambar 28.
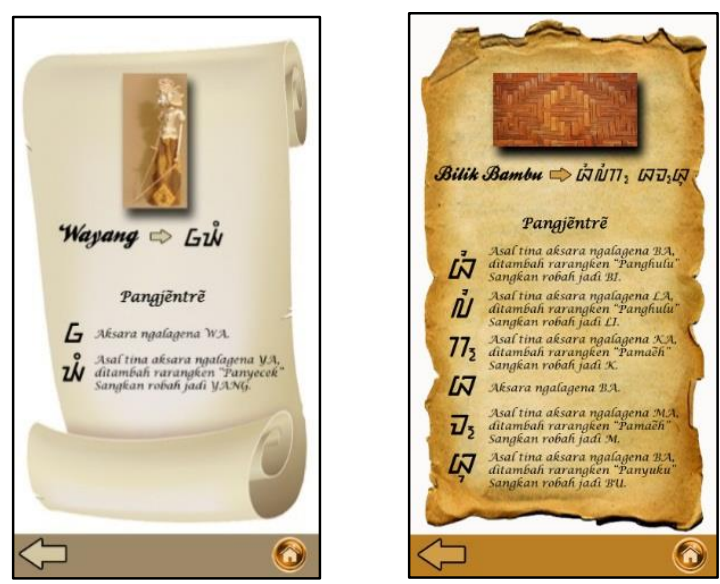

\section{Gambar 28 Tampilan contoh kecap}

\subsubsection{Penjelasan Rarangkén}

Berisi penjelasan dari rarangkén beserta contohnya, dan Tombol Tutup untuk menutup form dan kembali ke menu rarangkén. Tampilan penjelasan rarangkén dapat dilihat pada gambar 29. 


\subsubsection{Biodata}

$$
z_{1}=\text { panghulu }
$$

Pikeun ngarobah sora vokal

aksara dasar (Ngalagena)

/a/ jadi /i/

Contoh: $77=k a$ menjadi $77=k i$.

\section{Tutup}

\section{Gambar 29 Tampilan penjelasan rarangkén}

Berisi 1 text box dan 1 tombol. Text Box untuk mengisi nama pemain dan Tombol Simpan untuk menyimpan data ke database, serta masuk ke form skor untuk melihat skor yang diperoleh dan perolehan skor tertinggi. Tampilan biodata dapat dilihat pada gambar 30.

\subsubsection{Skor}

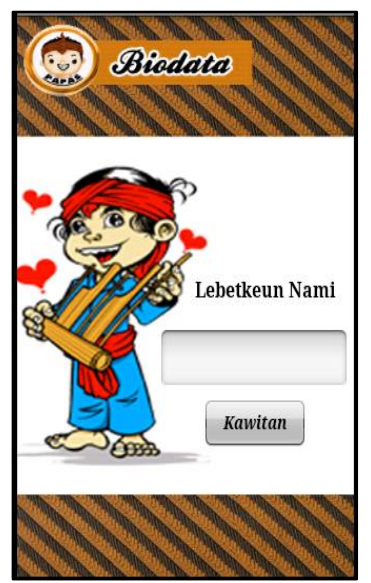

\section{Gambar 30 Tampilan biodata}

Berisi jumlah skor yang diperoleh, list perolehan skor dari yang tertinggi, dan Tombol icon home untuk kembali ke menu utama/home. Tampilan skor dapat dilihat pada gambar 31.

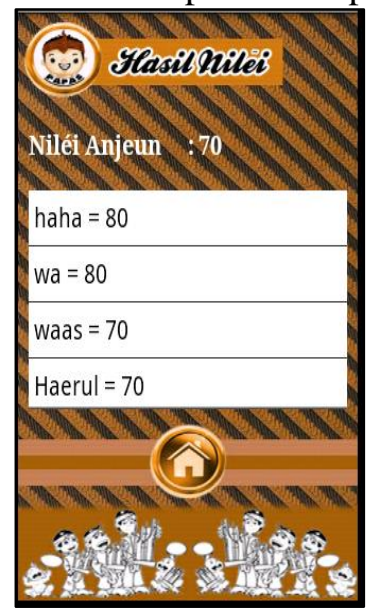

\section{Gambar 31 Tampilan skor}

\subsection{Pengujian}

Aplikasi game yang telah dibuat selanjutnya diuji melalui teknik pengujian perangkat lunak yang meliputi white box dan black box.

1. Pengujian White Box 
Yang dimaksud metode White box adalah suatu metode desain test case yang menggunakan struktur kontrol desain prosedural untuk memperoleh test case.

Pengujian dilakukan terhadap keseluruhan program secra utuh, namun pada menu kuis hanya dilakukan sampel pengujian terhadap salah satu pertanyaan. Sebagai contoh akan dibahas pengujian terhadap pertanyaan nomor 1, yang prinsip kerjanya sama dengan pertanyaan nomor-nomor berikutnya dari menu kuis ini. Secara garis besar, algoritmanya sebagai berikut:

a. Tampilan pertama pemain berada pada menu utama yang terdiri dari beberapa pilihan, yaitu menu aksara, rarangken, contoh kecap, kuis dan kaluar.

b. Jika pemain memilih menu aksara, maka muncul form menu aksara. Jika memilih menu rarangken, maka muncul form menu rarangken. Begitupun dengan pilihan menu lainnya.

c. Pada menu aksara terdapat 4 pilihan menu, yaitu aksara ngalagena, aksara serepan, aksara swara dan angka.

d. Pada menu rarangken terdapat bentuk-bentuk rarangken. Klik rarangken untuk melihat penjelasan dan fungsi dari rarangken yang dipilih.

e. Pada menu contoh kecap terdapat macam-macam gambar. Klik gambar untuk melihat translate dari bahasa indonesia ke aksara Sunda dari gambar tersebut beserta penjelasannya.

f. Pada menu kuis terdapat 10 pertanyaan tentang aksara Sunda dengan level tingkat kesulitan yang berbeda-beda.

g. Level 1 sampai 5 diberikan kesempatan 2 kali untuk menjawab, jika 2 kali menjawab salah maka kuis akan berakhir. Sedangkan level 6 sampai 10 hanya diberikan satu kali kesempatan.

h. Setiap pertanyaan yang dijawab dengan benar akan mendapatkan skor 10.

i. Sebeum memulai kuis,pemain diminta untuk mengisi nama.

j. Setelah semua pertanyaan terjawab atau salah dalam menjawab, akan tampil skor yang diperoleh dan list perolehan skor para pemain terurut dari skor yang tertinggi.

2. Pengujian Black Box

Dalam pengujian berikutnya dilakukan untuk memastikan bahwa suatu event atau masukan akan menjalankan proses yang tepat dan menghasilkan output sesuai dengan rancangan yang dibuat.

Tabel 1 Pengujian Black Box Menu Utama/Home

\begin{tabular}{|c|c|c|c|}
\hline $\begin{array}{l}\text { Input/ } \\
\text { Event }\end{array}$ & Proses & $\begin{array}{c}\text { Output/ } \\
\text { Next Stage }\end{array}$ & $\begin{array}{c}\text { Hasil } \\
\text { Pengujian }\end{array}$ \\
\hline $\begin{array}{l}\text { Tombel } \\
\text { Aksara }\end{array}$ & Activity.LoadLayout("aksara") & $\begin{array}{c}\text { Menampilkan } \\
\text { form menu } \\
\text { aksara }\end{array}$ & Sesuai \\
\hline $\begin{array}{l}\text { Tombel } \\
\text { Rarangken }\end{array}$ & Activity.LoadL ayout("rarangken") & $\begin{array}{l}\text { Menampilkan } \\
\text { form menu } \\
\text { rarangken }\end{array}$ & Sesuai \\
\hline $\begin{array}{l}\text { Tombel } \\
\text { Contoh } \\
\text { Kecap }\end{array}$ & Activity.LoadLayout("contoh") & $\begin{array}{l}\text { Menampilkan } \\
\text { form menu } \\
\text { contoh kecap }\end{array}$ & Sesuai \\
\hline Tombol Kuis & Activity.LoadLayout("kuis") & $\begin{array}{l}\text { Menampilkan } \\
\text { form kuis }\end{array}$ & Sesuai \\
\hline $\begin{array}{l}\text { Tombol } \\
\text { Keluar }\end{array}$ & $\begin{array}{c}\text { Msgbox("Jaga tur Piara Warisan Budaya } \\
\text { Sunda..!","Panutup") } \\
\text { mp.Load(File.DirAssets,"Kacapi } \\
\text { suling.mp3") } \\
\text { mp.Stop } \\
\text { Activity.Finish }\end{array}$ & $\begin{array}{l}\text { Tampil message } \\
\text { box lalu keluar } \\
\text { dari aplikasi }\end{array}$ & Sesuai \\
\hline
\end{tabular}

Pada tabel 1 dilakukan pengujian black box pada menu utama/home, hasil pengujian menampilkan input, proses dan output sesuai dengan keinginan/sukses 
Tabel 2 Pengujian Black Box Menu Aksara

\begin{tabular}{|cccc|}
\hline $\begin{array}{c}\text { Input/ } \\
\text { Event }\end{array}$ & Proses & $\begin{array}{c}\text { Output/ } \\
\text { Next Stage }\end{array}$ & Hasil \\
Pengujian \\
\hline $\begin{array}{c}\text { Tombol } \\
\text { Aksara } \\
\text { Ngalagena }\end{array}$ & Activity.LoadLayout("ngalagena") & $\begin{array}{c}\text { Menampilkan } \\
\text { form menu } \\
\text { aksara }\end{array}$ & Sesuai \\
\hline $\begin{array}{c}\text { Tombal } \\
\text { Aksara } \\
\text { Serepan }\end{array}$ & Activity.LoadLayout("serepan") & $\begin{array}{c}\text { Menampilkan } \\
\text { form menu } \\
\text { rarangken }\end{array}$ & Sesuai \\
\hline $\begin{array}{c}\text { Iombal } \\
\text { Aksara } \\
\text { Swara }\end{array}$ & Activity.LoadLayout("swara") & $\begin{array}{c}\text { Menampilkan } \\
\text { form menu } \\
\text { contoh kecap }\end{array}$ & Sesuai \\
\hline $\begin{array}{c}\text { Tombol } \\
\text { Angka }\end{array}$ & Activity.LoadLayout("angka") & $\begin{array}{c}\text { Menampilkan } \\
\text { form angka }\end{array}$ & Sesuai \\
\hline
\end{tabular}

Pada tabel 2 dilakukan pengujian black box pada menu aksara, hasil pengujian menampilkan input, proses dan output sesuai dengan keinginan/sukses

Tabel 3 Pengujian Black Box Menu Rarangkén

\begin{tabular}{|c|c|c|c|}
\hline $\begin{array}{l}\text { Input' } \\
\text { Event }\end{array}$ & Proses & $\begin{array}{c}\text { Output' } \\
\text { Next Stages }\end{array}$ & $\begin{array}{c}\text { Hasil } \\
\text { Pengujian }\end{array}$ \\
\hline $\begin{array}{l}\text { Gambar } \\
\text { Panghulu }\end{array}$ & Activity.LoadLayout("Porghulu") & $\begin{array}{c}\text { Menxmapilian } \\
\text { form Penjelasan } \\
\text { Panghulu }\end{array}$ & Sesuai \\
\hline $\begin{array}{l}\text { Gambar } \\
\text { Pamerpot }\end{array}$ & Activity.LoadLayout("Pamepet") & $\begin{array}{c}\text { Menxmpilian } \\
\text { form Penjelasan } \\
\text { Pconcpet }\end{array}$ & Sesuai \\
\hline $\begin{array}{c}\text { Gambar } \\
\text { Peneulewg }\end{array}$ & Activity Loadilayout("Penculewy ") & $\begin{array}{c}\text { Menxmpilkan } \\
\text { form Penjelasan } \\
\text { Penewleung }\end{array}$ & Sesuai \\
\hline $\begin{array}{l}\text { Gambar } \\
\text { Pargiavar }\end{array}$ & Activity Loadi_ayout("Pangiayar") & $\begin{array}{c}\text { Meninapilkan } \\
\text { form Penjelasan } \\
\text { Pangilavar }\end{array}$ & Sesuai \\
\hline $\begin{array}{l}\text { Gambar } \\
\text { Parpecek }\end{array}$ & Activity LoadL ayout("Papvecek") & $\begin{array}{c}\text { Mennmapilkan } \\
\text { form Penjelasan } \\
\text { Panjecek }\end{array}$ & Sesuai \\
\hline $\begin{array}{l}\text { Gambar } \\
\text { Paryuku }\end{array}$ & Activity.LoadLayout ("Panyuku') & $\begin{array}{c}\text { Menxmapilian } \\
\text { form Penjelasan } \\
\text { Penviku }\end{array}$ & Sesuai \\
\hline $\begin{array}{l}\text { Gambar } \\
\text { Pavyalora }\end{array}$ & Activity.LoadL_yout("Paryabra ") & $\begin{array}{c}\text { Menxmpilkan } \\
\text { form Penjelasan } \\
\text { Powabra }\end{array}$ & Sesuai \\
\hline $\begin{array}{l}\text { Gambur } \\
\text { Paryiku }\end{array}$ & Activity.LoadLayout("Pavyiku") & $\begin{array}{c}\text { Menamipilkan } \\
\text { form Penjelasan } \\
\text { Perviku }\end{array}$ & Sesuai \\
\hline $\begin{array}{l}\text { Gambar } \\
\text { Paneieng }\end{array}$ & Activity Loadi.ayout("Paneleng ") & $\begin{array}{c}\text { Meninupilkan } \\
\text { form Penjelasan } \\
\text { Pareleres }\end{array}$ & Sesuai \\
\hline $\begin{array}{l}\text { Gambar } \\
\text { Panolong }\end{array}$ & Activity.LoadL_ayout("Panolong ") & $\begin{array}{c}\text { Menxmapilian } \\
\text { form Penjelasan } \\
\text { Panolong }\end{array}$ & Sesuai \\
\hline $\begin{array}{c}\text { Gambar } \\
\text { Panuingkal }\end{array}$ & Activity Loadilayout("Pantingkal ") & $\begin{array}{c}\text { Menxmapilian } \\
\text { form Penjelasan } \\
\text { Paningrkal }\end{array}$ & Sesuai \\
\hline $\begin{array}{c}\text { Gambar } \\
\text { Paysurisad }\end{array}$ & Activity Loadl_ayout("Payguitad") & $\begin{array}{c}\text { Menxmilikan } \\
\text { form Penjelasan } \\
\text { Panguisad }\end{array}$ & Sesuai \\
\hline $\begin{array}{l}\text { Gambar } \\
\text { Panaeh }\end{array}$ & Activity Loadlayout("Panvaen") & $\begin{array}{c}\text { Menamipilkan } \\
\text { form Penjelasan } \\
\text { Pon:aeh }\end{array}$ & Sesuai \\
\hline $\begin{array}{c}\text { Tocobal icon } \\
\text { Howne }\end{array}$ & Activity.LoadLayout("menu") & $\begin{array}{c}\text { Menimailkan } \\
\text { fonw menu } \\
\text { utama }\end{array}$ & Sesuai \\
\hline
\end{tabular}

Pada tabel 3 dilakukan pengujian black box pada menu rarangkén, hasil pengujian menampilkan input, proses dan output sesuai dengan keinginan/sukses 
Tabel 4 Pengujian Black Box Menu Contoh Kecap

\begin{tabular}{|c|c|c|c|}
\hline $\begin{array}{l}\text { Input/ } \\
\text { Butil }\end{array}$ & Proses & $\begin{array}{l}\text { Output } \\
\text { Next Sige }\end{array}$ & $\begin{array}{c}\text { Hasil } \\
\text { Pengujian }\end{array}$ \\
\hline $\begin{array}{c}\text { Oambar Bilik } \\
\text { Bumbi }\end{array}$ & Actirity LoadLayout((bilk) & $\begin{array}{c}\text { Menampikan } \\
\text { form bilik }\end{array}$ & Sesuai \\
\hline Gambar Sawah & Actnity LoadLayout("'awah") & $\begin{array}{l}\text { Menampilkan } \\
\text { form swah }\end{array}$ & Sesuai \\
\hline Gambar Saron & Activity LoadLayout("saron') & $\begin{array}{l}\text { Menampilkan } \\
\text { form safon }\end{array}$ & Sesuai \\
\hline $\begin{array}{l}\text { Gambar } \\
\text { Kendang }\end{array}$ & Activity LoadLayout('Kendang) & $\begin{array}{l}\text { Menampikan } \\
\text { form kendang }\end{array}$ & Seruai \\
\hline $\begin{array}{c}\text { Gambar } \\
\text { Kacapi Suling }\end{array}$ & Actirity LoadLayout("kacapi") & $\begin{array}{c}\text { Menampikan } \\
\text { form kacapi } \\
\text { suling }\end{array}$ & Sesuai \\
\hline $\begin{array}{l}\text { Cambar } \\
\text { Karinding }\end{array}$ & Actrity LoadLayout(karinding") & $\begin{array}{l}\text { Menampilkan } \\
\text { brin karinding }\end{array}$ & Sesuai \\
\hline $\begin{array}{l}\text { Ganbar Ihet } \\
\text { Sunda }\end{array}$ & Activity LoadLayout("iket) & $\begin{array}{l}\text { Menampilkan } \\
\text { form ihet Sunda }\end{array}$ & Sesuai \\
\hline Gambar Batik & Activity LoadLayout(batk) & $\begin{array}{c}\text { Menampilkan } \\
\text { fom batik }\end{array}$ & Sesuai \\
\hline $\begin{array}{l}\text { Gambar } \\
\text { Kujang }\end{array}$ & Activity LoadLayou(" kujang") & $\begin{array}{l}\text { Menampikan } \\
\text { fom kujang }\end{array}$ & Sesuai \\
\hline $\begin{array}{c}\text { Gambar } \\
\text { Astrajingga/ce } \\
\text { pot }\end{array}$ & Activity LoadLayout("cepot) & $\begin{array}{l}\text { Menampilkan } \\
\text { form cepot }\end{array}$ & sesuai \\
\hline $\begin{array}{l}\text { Gambar } \\
\text { Argklung }\end{array}$ & Activity LoadLayout("angklung") & $\begin{array}{l}\text { Menampilkan } \\
\text { form angklung }\end{array}$ & sesuai \\
\hline $\begin{array}{l}\text { Oambar } \\
\text { Wayanz }\end{array}$ & Activity LoadLayout("wayang) & $\begin{array}{l}\text { Menampilkan } \\
\text { brm wayse }\end{array}$ & sesuai \\
\hline $\begin{array}{c}\text { Tombol icon } \\
\text { Home }\end{array}$ & Activity LoadLayout(meno') & $\begin{array}{c}\text { Menampikan } \\
\text { form nenu } \\
\text { utama }\end{array}$ & Sesuai \\
\hline
\end{tabular}

Pada tabel 4 dilakukan pengujian black box pada menu contoh kecap, hasil pengujian menampilkan input, proses dan output sesuai dengan keinginan/sukses 
Tabel 5 Pengujian Black Box Menu Kuis

\begin{tabular}{|c|c|c|c|}
\hline $\begin{array}{l}\text { Input } \\
\text { Everis }\end{array}$ & Proues & $\begin{array}{l}\text { Cutput } \\
\text { Next Stage }\end{array}$ & $\begin{array}{l}\text { Masul } \\
\text { Penguian }\end{array}$ \\
\hline $\begin{array}{l}\text { Topber: } \\
\text { Jenzbar: } \\
\text { Benar }\end{array}$ & Activity Losdte ayout("sosil2") & $\begin{array}{l}\text { Metcemplican } \\
\text { form pertasyzen } \\
\text { nomor } 2\end{array}$ & Sesuzi \\
\hline $\begin{array}{l}\text { Togabe: } \\
\text { Janabat } \\
\text { Salah! }\end{array}$ & 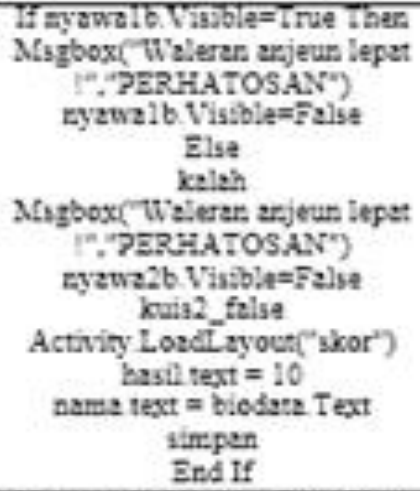 & 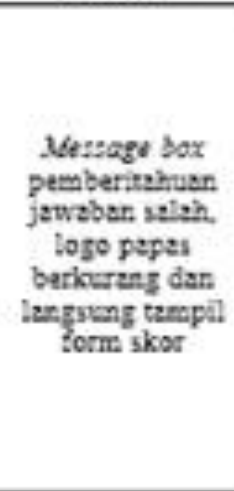 & Servel \\
\hline $\begin{array}{l}\text { Touble: } \\
\text { Jerreban } \\
\text { Salah? }\end{array}$ & 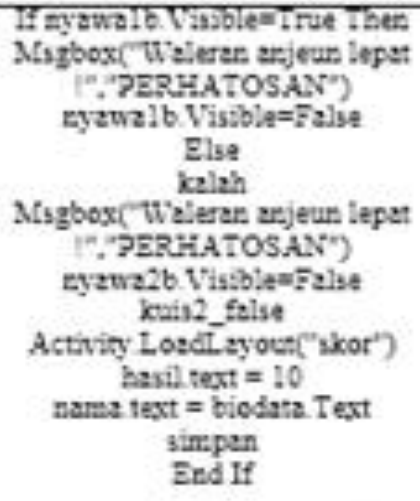 & 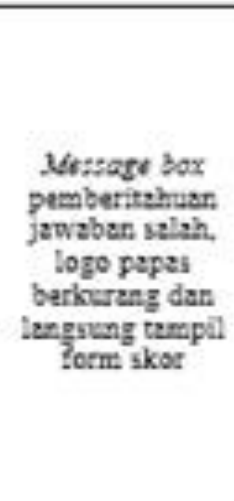 & Sesuxi \\
\hline $\begin{array}{l}\text { Tombo: } \\
\text { Jonabat } \\
\text { Solah } 3\end{array}$ & 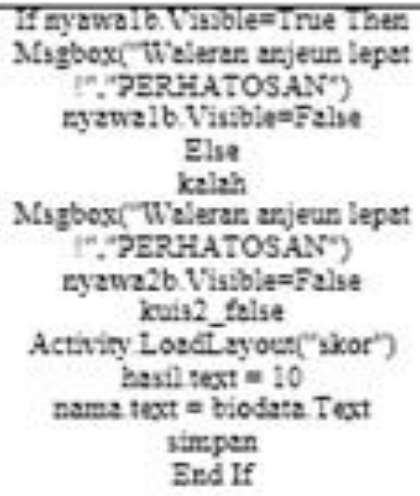 & 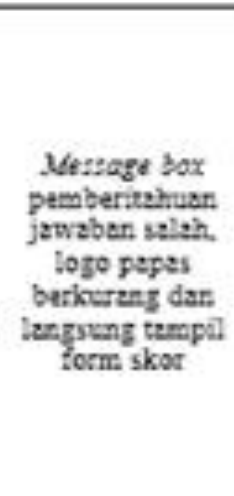 & Servei \\
\hline
\end{tabular}

Pada tabel 5 dilakukan pengujian black box pada menu kuis, hasil pengujian menampilkan input, proses dan output sesuai dengan keinginan/sukses

\section{KESIMPULAN}

Program aplikasi pembelajaran aksara sunda berbasis android yang telah dibuat sangat bermanfaat bagi siswa-siswi dalam membantu pemahaman mereka terhadap pelajaran aksara sunda. Dengan adanya tampilan multimedia animasi dan dilengkapi dengan musik membuat pembelajaran lebih menarik serta tidak monoton. Penggunaan media pembelajaran handphone membuat waktu belajar lebih fleksibel bisa dmanapun dan kapanpun. Aplikasi pembelajaran aksara sunda ini telah dicoba digunakan oleh siswasiswi SMAN 1 Singaparna. 


\section{REFERENSI}

[1] Tim Unicode Aksara Sunda. 2008. Direktori Aksara Sunda untuk Unicode jilid 1. Bandung. Pemerintah Provinsi Jawa Barat Dinas Pendidikan Provinsi Jawa Barat.

[2] Attewell, Jill. 2009. The Impact Of Mobile Learning. LSN

[3] H. B. Seta, T. Wati, I. T. Mudakurniawan, "ANALISIS DAN PERANCANGAN APLIKASI MOBILE LEARNING BERBASI ANDROID," Seminar Nasional Teknologi Informasi dan Multimedia 2015, ISSN : 2302-3805.

[4] M. F. Adiwisastra, "Perancangan Game Kuis Interaktif Sebagai Multimedia Pembelajaran Drill and Practice Untuk Meningkatkan Hasil Belajar Siswa," J. Inform., vol. 2, no. 1, pp. 205-211, 2016, doi: 10.31311/ji.v2i1.67.

[5] A. Herliana, "ANIMASI INTERNAKTIF PEMBELAJARAN TARI MERAK Asti,” vol. II, no. 2, pp. 453-464, 2015.

[6] P. A. Nurcahyo, "Pengaruh Media Pembelajaran Aplikasi Android Terhadap the Effects of Android Application Learning Media on Students '," pp. 337-344, 2012.

[7] S. Fatimah and Y. Mufti, "Pengembangan Media Pembelajaran IPA-Fisika Smartphone Berbasis Android Sebagai Penguat Karakter Sains Siswa," J. Kaunia, vol. X, no. 1, pp. 59-64, 2014.

[8] L. Rahmelina, Y. Huda, P. Studi, P. Teknik, F. Teknik, and U. Negeri, "APLIKASI MOBILE LEARNING ILMU BIOLOGI UNTUK SISWA KELAS X SEKOLAH MENENGAH ATAS BERBASIS ANDROID (Studi Kasus SMA N 10 Padang," J. Vokasional Tek. Elektron. Inform. Vol., vol. 2, no. 2, pp. 2-7Rahmelina, L., Huda, Y., Studi, P., Teknik, P., 2014.

[9] Pribadi, Ganteng Eki, Undang Syaripudin dan Wisnu Uriawan. "Aplikasi Pembelajaran Bahasa Sunda dengan Implementasi Algoritma Linear Congruental Generator dan Fuzzy Berbassi Android," JOIN. Vol.I No.1 Juni 2016: 34-42

[10] Black, Rex. 2007. Pragmatic Software Testin: Becoming an Effective Test Professional. Hoboken: Wiley Publishing Inc

[11] Daryanto. 2008. Belajar Komputer Animasi Macromedia Flash. Bandung: Yrama Widya

[12] Safaat, Nazaruddin. 2012. ANDROID Pemerograman Aplikasi Mobile Smartphone dan Tablet PC Berbasis Android. Bandung. Informatika

[13] Sakti, Gita Tresna, Asep Suryana dan Agus Setiaman. 2012. Komunikasi Instruksional Pengajar Dalam Membentuk Sikap Anggota Untuk Melestarikan Aksara Sunda Sebagai Budaya Sunda. Bandung: Jurnal Mahasiswa Universitas Padjajaran. Vol.1, No.1 2012: 1-16.

[14] Kustandi, Cecep dan Bambang Sutjipto. 2013. Media Pembelajaran Manual dan Digital. Bogor: Ghalia Indonesia.

[15] Riyanto, Verry. Animasi Interaktif Pengenalan Aksara Jawa Pada Anak Siswa Sekolah Dasar. 2014. ISSN: 2089-8711. Vol. III, No. 2, 2014. 298-302. 